\title{
Creative Universities in the Digital Age: Transformation of Academic Traditions and New Strategies
}

\author{
Tatiana Sidneva ${ }^{1, *}$, Vladimir Musichenko ${ }^{2}$, Alexander Gudkov ${ }^{1}$ \\ ${ }^{1}$ Glinka Nizhny Novgorod State Conservatoire, Nizhny Novgorod, Russia \\ ${ }^{2}$ Moscow State Academy of Applied Art and Design named after Sergei Stroganov, Moscow, Russia \\ *Corresponding author. Email: iesokol@yandex.ru
}

\begin{abstract}
The article considers the main factors that determined the transformation of the structure and functions of higher art education in the digital age. The new possibilities of creative universities are analyzed and the prospects for their development are identified. The technological breakthrough that is characteristic of all spheres of digital civilization has led to a change in the ways of art existence, a revision of the traditional parameters of creativity, and a rethinking of the hierarchy of artistic values. The emergence of virtual tools, new ways of processing, storing and broadcasting artistic information, expanding the boundaries of figurative and symbolic perception-all this has determined the need for the development of new knowledge, the introduction of new creative specialties, the development of modern foundations of art management, etc. At the same time, the digital age has raised the question of the need to preserve fundamental academic traditions with greater urgency. The authors come to the conclusion about the unprecedented responsibility of modern creative universities in forming the personality of an artist who is aware of his mission in culture.
\end{abstract}

Keywords: transformation of the structure and functions of higher art education in the digital age, new opportunities for creative universities, the formation of the artist's personality.

\section{INTRODUCTION}

Innovative digital technologies completely penetrate into all spheres of life, opening up new communication opportunities, radically changing the world. Innovative digital technologies completely penetrate into all spheres of life, opening up new communication opportunities, radically changing the world. A tremendous amount of information becomes available, increasing with steady acceleration and exposing the problem of choice in this multidimensional flow. There has been a rethinking of concepts and perceptions that until recently seemed unshakable. Open and «permeable» are the boundaries of different forms of culture - science, art, religion, politics, education, everyday life. The powerful influence of integration processes transcends the sovereign territories of local traditions, giving way to metanational, hyperand transnational phenomena. «In some sense, each product is a product of transnational collective creativity and labor» $[1,21]$.

The modern cultural situation, which is widely covered in the scientific literature $[2 ; 3 ; 4 ; 5]$, it inevitably affects the state of education, since it belongs to those areas that are particularly sensitive to the state of culture. «The state of the school - both general and special-is perhaps the most sensitive indicator of culture» $[6,304]$.

It is obvious that the problem of a broad and principled discussion of the state of the schools and ways of improving them is connected not only with the solution of economic, legal, organizational, educational and methodological issues. The starting point of the discussion should be a philosophical understanding of the essential problems of education, the definition of its fundamental bases and strategies.

Digitalization of education is a complex, multidimensional, far from unambiguous process. Today different specialists are involved in the discussion of the concept of the «digital university» model. Obvious advantages: free access to the up-to-date information, objective assessment of knowledge, accelerated acquisition of various skills - contribute to the development of students' creative abilities, help to fully reveal the intellectual potential of young people. At the same time, due to the introduction of digital technologies, 
a radical update of the concept of education does not remove the importance of personal contact between an authoritative teacher and a student, professor and student who is starting his professional career, as well as real communication between the student and his peers. Education as a productive intellectual, intuitive and emotional process is now at the epicentre of discussions about the humanistic meaning of a various professions.

Creativity is one of the universal strategies of education in general. At the same time, according to the established tradition of «creative» higher education institutions mean those educational institutions that train specialists in the field of art - artists, writers, musicians, actors, directors, architects, designers.

From the organizational and financial-economic standpoint, higher education in the sphere of art is one of the most «inconvenient» problems. These «inconveniences» are caused by the specifics of creative universities: the need for individual training, the preservation of the personal factor of transferring skills, knowledge and traditions, the inadmissibility of the flowconveyor method of training a composer, musicianperformer, painter, sculptor, actor, the impossibility of productive pedagogical work with a student in online mode, the low efficiency of distance learning, etc.

Let's add to the above-mentioned features the high labor intensity of creative professions: for example, to prepare a full-fledged specialist-musician, 18-20 years of intensive work are required (art school, music school, university, assistant internship). Finally, there is a wellknown problem of «planning» talented applicants of creative universities (nature gives our planet geniuses according to an unknown plan!!)

The quantitative indicator is no less significant here: the number of students of art universities is disproportionately smaller than in universities responsible for other specialties. The number of educational institutions of higher art education is also small. In this regard, there may be an illusion that the problem stated in the title of this article has a very specific and local character and does not have a fundamental impact on the state of modern education as a whole.

Nevertheless, there are common grounds in the problem and they are based on an understanding of the role of art in culture and its ability to influence the way of life, the way of thinking, self-identification of a person-regardless of his age, profession, religious and political beliefs, social status.

Art is the subject of study and development within the various disciplines taught at the art university: from the specialty (in the conservatory it is instrumental performance, vocal performance, conducting, composition; in design education-design and digital technologies, etc.) to the general history of art, communication theory, aesthetics, cultural studies and philosophy. In other words, the curriculum covers the entire vertical of artistic reality: from solving professional, «narrow-shop» tasks to determining the ontological, epistemological, axiological foundations of art. This academic tradition, developed over many decades, is designed to give the future artist a comprehensive understanding of the artistic experience.

\section{PROBLEM STATEMENT}

The technological breakthrough that determined the formation of a digital civilization led to a change in the ways of art's existence. The man has received tremendous opportunities to join the huge reservoir of artistic memory. These capabilities allowed him to overcome time and space, making available audio and video recordings, online broadcasts of festivals, exhibitions, theatrical performances; "smart" gadgets are able to broadcast the texts of books, samples of film products. Internet sites and mobile applications have created a comfortable environment for the perception of art.

One of the characteristic features of the digital age is «the introduction of comfort into human life and society as a whole, with the highest degree of comfort» [7, 23]. The natural consequence of the desire for convenience and comfort was the dominance in the art of entertainment. The subordination of the entertainment industry led to a rethinking of the hierarchy of artistic values, at the top of which shows, performance, and action were firmly established.

The natural consequence of the introduction of digital technologies in everyday life was the process of "mass" culture-a process that is far from being unambiguous. Along with the well-known positive factors, the ways of "desacralizing" art (V. Benjamin), subordinating it to the flow-conveyor industry, and commercializing the creative process and its results were opened.

An equally contradictory consequence of digitization was the phenomenon that J.Baudrillard also referred to as «aestheticization» of the cultural environment. The universally adopted aesthetic criterion is becoming a dominant, imperative that determines the significance of the natural environment, the world of things, the personal qualities of a person. Describing modern civilization, Baudrillard writes: The law that is imposed on us is the law of mixing genres. Everything is sexy, everything is political, everything is aesthetic» $[8$, pp. 16]. External attraction attractiveness displaces other values. The quality of food is often determined by the bright packaging, the value of clothing - by the brand name of the manufacturer, the body health - by the body built by cosmetic procedures and plastic surgery. The very interpretation of the aesthetic, understood from antiquity as the harmony of the inner revealed in the outer, is narrowed and often replaced by the cosmetic, erotic, and 
commercially successful. In the process of «aestheticizing» culture, Kant's justification of aesthetic creativity as the highest manifestation of a «disinterested», anti-utilitarian attitude to reality became redundant. «Expediency without purpose» turns into real expediency, revealing purely utilitarian meanings.

In this situation, art changes its mission. «Art with a capital letter is disappearing. Everything becomes Entertainment with a capital letter, or everything becomes art, but with a small letter» [9, p. 9]. The trembling distance that invariably marked «tension» of the borders of art and non-art has disappeared. Deeply embedded in everyday life, even high academic art appears to us "adapted" to everyday life (an example of this is the use of classical music as a background for advertising goods and services).

The «onslaught» of digitalization is radically changing the language of art. The uniqueness of the modern artistic experience lies in the linguistic kaleidoscopicity of the utterance. At the same time, the established polylinguism has a characteristic bidirectionality. On the one hand, the process of «massing» and commercializing culture often encourages professional artists to simplify the language (to the point of primitiveness and routine). On the other hand, there is an opposite tendency associated with daring experiments that led to the transformation of the ontological foundations of art: radical futuristic experiments with color and form in the visual arts, a revolution in the field of sound and its organization in music, a total synthesis of arts and art practices.

One of the newest events in combining high computer technology and artistic experience is «procedural» or «generative» art, which «creates itself» using an autonomous system, and assumes minimal participation of the author. British experimental composer Brian Eno in 2012 created an iPad application (called "Scapes"), capable of generating visual and audio images. «As a composer, I was interested in creating a system or process that would 'compose music for you', you will only have to set some initial conditions that the system would transform and create something that you could not have foreseen» [10]. Today «generative art» is firmly embedded in the artistic practice of industrial and graphic design [11], architecture and other types of art - making it even more difficult to find answers to one of the main questions of modernity: «What is art?».

Even on the basis of a brief description of the current situation, reflecting a radical revision of the traditional parameters of art, it becomes obvious how difficult the tasks of academic art education today are.

\section{MATERIALS AND METHODS}

The original mission of creative universities is to preserve academic specialties in the field of art.
Noteworthy are the definitions of classical creative universities: «conservatory», derived from the Latin «conservare» - «preserve»; «academy», etymologically going back to the Platonic school, etc. The attitude to following the tradition means, first of all, turning to the centuries - old, time-tested, artistic experience-the experience of self-knowledge and self-esteem of a person, the knowledge of the tools of artistic research of life tested in different epochs.

At the same time, it is very important to understand that this attitude is not a sign of conservatism and low mobility of the structure of a creative university. The role of classical artistic values in the space of human existence is related to the meaning of the symbol. As Y. M. Lotman writes, «there is always something archaic in a symbol. Every culture needs a layer of texts that perform the function of archaic. The thickening of symbols is usually particularly noticeable here» $[12,191]$. "As" an eternal sign of genuine art" (D. Merezhkovsky), the symbol "always dark in its depth" (Viach. Ivanov). It determines the diversity, meaningfulness and inexhaustibility of understanding the history of artistic experience" [6, 222]. Thus, the need to connect to the continuum of history for an aspiring artist is the starting platform for the most daring futuristic ideas and creative experiments.

Note that this is the internal dramatic contradiction of the pedagogy of creativity: «every school is learning the known, mastering knowledge, reception, matrix, that is, the finished result, but it is necessary to form a personality that can overcome the school, because creativity is always a breakthrough into the unknown, the implementation of forms of activity that do not yet exist» $[13,305]$. But it is this "inner drama" that is most productive in the modern concept of higher art education.

\section{RESULTS AND DISCUSSION}

Academic institutions of art today are quite mobile. In addition to the traditional ones, they have introduced and licensed new creative specialties and specializations that are in demand by the time. Non-academic genres of music, digital literature, new technologies of sound engineering, media journalism, digital design are being studied. The era of information development led to the opening of specialty «art management» in many universities of art, the creation of appropriate departments and faculties.

The introduction of digital technologies has put design at the forefront of creative professions. One of the youngest of the most relevant specialties, design is directly related to the level of digital technologies and in a very short time has passed a rapid path from the utilitarian and applied sphere to a new synthesis of artistic and technical aspects.

Now design is a complex differentiated system in which a huge number of independent industries coexist 
(information, graphic, book, landscape architecture, motion design, web design, sound design, future design, etc.) $[14,203]$.

The ability to use computer programs, awareness of their constant updating, as well as digital competencies in general, do not guarantee a young person a successful career advancement. Modern reality has required the designer to know the theory and history of art, since design is inseparable from understanding the laws of the artistic genre and style process. An important step in entering the profession is the ability to navigate the current phenomena of artistic practice.

It should be noted that broad erudition and digital literacy "work" in the design profession only when they exist on the platform of a developed artistic and design consciousness. Figurative and metaphorical thinking, the ability of symbolic generalization, the heuristic attitude of the individual to materialize the idea in the composition - these attributes of artistic creativity are associated with the scale of culture as a whole.

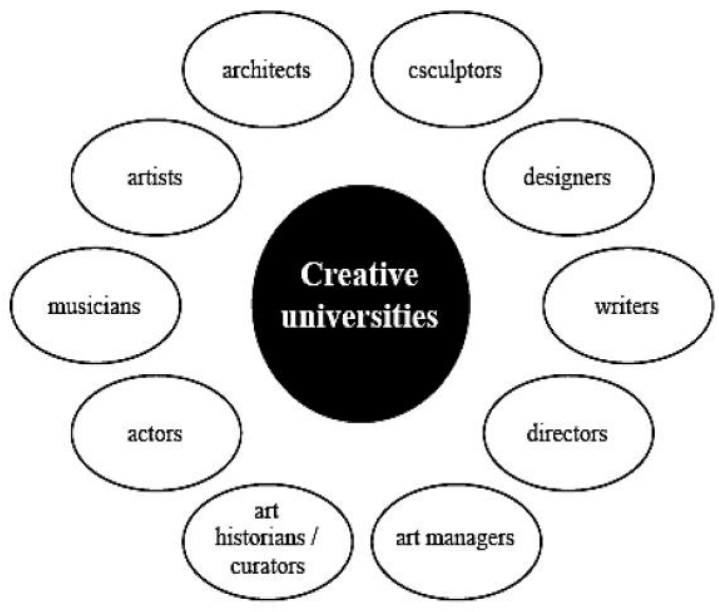

Figure 1 Training of specialists in creative universities

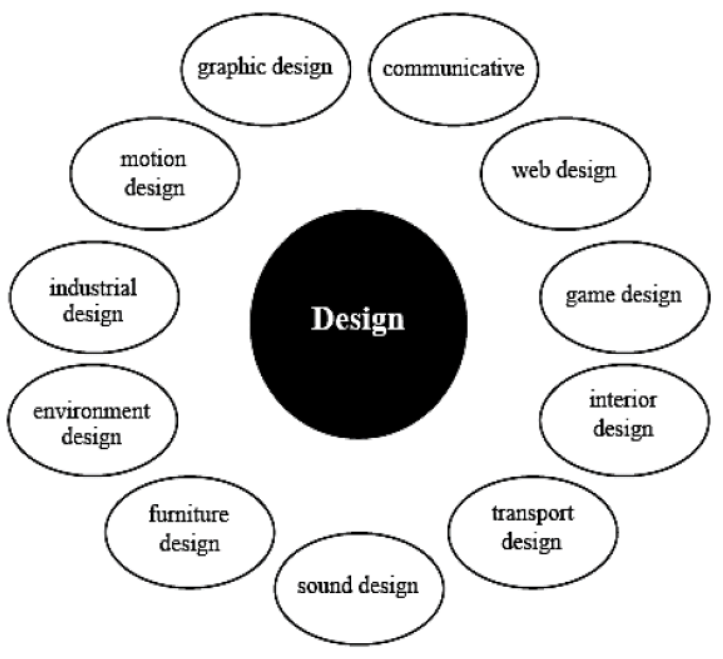

Figure 2 Modern design trends
The main vector of design development was the fact that design based on established canons «gives way to the search for the author's style and bright concepts» [15, 399]. It should not be forgotten that the designer who creates the project of any phenomenon or event (exhibitions, festivals, publications, brands, etc.), actually participates in the creation of the visual image of the world as a whole. In this way, he is involved in shaping the tastes, preferences, and values of society. This is the special responsibility of the author for his creation - a work of design art. In this regard, it is appropriate to recall M. Bakhtin's early work «Art and Responsibility», in which he writes about the mutual responsibility and mutual guilt of art and life: «The poet must remember that his poetry is to blame for the vulgar prose of life, and let the man of life know that the fruitlessness of art is to blame for its undemandingness and the frivolity of its life questions»[16, 54].

In the modern lexicon, the concepts of «guilt» and «responsibility» seem unpopular and pretentious. Nevertheless, M. Bakhtin's judgment, formulated more than a hundred years ago (1919), is an important reminder of the original and enduring mission of art. Understanding the creative, informative, communicative, technical tasks of the artist's profession has existential foundations and, ultimately, has access to the global problems of life.

In the academic training of a designer, there is a significant feature that makes it possible to see in him a model of a modern artist. The concepts of «text», «context», «communication» acquire a comprehensive character for the designer: «... the vector of the profession has turned towards communication, which forms a model of design of a procedural nature» $[17,401]$.

Creativity and design skills must necessarily be combined with an awareness of the importance of modern communications. The designer cannot be "detached" from reality, but is able to work with the customer, navigate in the utilitarian and pragmatic areas of culture (project budget, technological framework, deadlines, etc.), have the skills and knowledge of management. It is all the more important to emphasize the "human" dimension of the creative specialty.

A power of influencing on the tastes and preferences of society and, at the same time, responsibility for them is also characteristic of art management - a specialty that has taken a firm place in the system of art education. As all art is steadily moving into digital format, so art management is gradually modulating into the science and art of managing the digital viewer, listener, and reader.

«In the past, the most important thing was the individual, in the future, the most important thing will be the system," - so in 1911, f. Taylor predicted the development of industrial production management [18]. The same words, more than a century later, can be 
attributed to the field of art object management - a specific and insufficiently studied field of management. An art object in this case means any project, organization or structure related to art and which aims to optimize one or more management criteria: from profit to viewing, listening, visiting, bought tickets or critics' ratings and much more. The proximity to the optimal value of these criteria will characterize the effectiveness of art management, and the process of managing an art object can be called multi-criteria optimization of the selected indicators and the application of appropriate control actions and measures to achieve the established optimal indicators.

\section{CONCLUSION}

In the conditions of saturation of the information and cultural space, in the absence of a built-up art management technology, many promising art objects are closed or lost in the flow of information that is useless for the consumer. The management of an art object may have different assessments of the optimality criteria, and maximizing them does not always lead to achieving the best result. This leads to the conclusion that there is a need for an interim assessment of optimality and correlation of management results with the values of criteria predicted during the development of the strategy. Based on this, it is clear that the question of the relevance and need for the development of art management and training of specialists in this field is quite acute.

At the same time, we emphasize that the inclusion of the specialty «art management» in the context of art education has a serious argument. The formation of a fully-built art management system-along with knowledge of economics, communication theory, history and entrepreneurship theory - is unthinkable without understanding the specifics of art «from the inside».

The current situation requires an active involvement of an art student (regardless of his future professionactor, musician, director, designer or manager) in reflections about aesthetic values, the fate of art, its essence and functions in culture. It is the activity of the position that will help the young person to adequately assess the current state of culture, to distinguish the authentic from the surrogate, artistic values from the ersatz samples, to understand the true meaning of creativity.

Higher artistic education is proving to be the most important stage in the development of the world view of musicians, actors, artists and directors. Therefore, all disciplines that collectively study art in its entirety have a special significance. It is important for a talented person not only to be able to do a lot and find the author's language in their profession, not only to understand the tasks and meaning of their activities. It is extremely important to be heard, and to do this, learn to publicly give a reasoned assessment of various cultural phenomena.

Modern education should be relevant and in demand, the student needs to receive information that will help him to most effectively produce, consume, integrate into the modern digital world. Innovative methods and technologies of training, of course, should be implemented. Education, like any other sphere of life, cannot but be modernized, the importance of any specialty directly depends on improving the effectiveness of teaching technical skills.

However, with the universal algorithmization and virtualization of education, all innovations should in no case capture even a small "patch" of the territory of consciousness responsible for personal growth, the ability to think critically and form opinion. However, with the universal algorithmization and virtualization of education, all innovations should in no case capture even a small "patch" of the territory of consciousness responsible for personal growth, the ability to think critically and form opinions. Otherwise, we "risk getting a global totalitarian system of a new type, based on the unique possibilities of manipulating the consciousness of both an individual and society as a whole" $[6,23]$. The above is fully relevant for art education.

In general, the problems formulated in the article are still waiting for their fundamental and comprehensive discussion.

\section{REFERENCES}

1. V.V. Mironov, Age of globalization. Research of modern global processes 1(9) (2012) pp. 20-33. DOI: https://doi.org/10.30936 / 2227-7951-201810-25-37.

2. G.B. Kleiner, Predictability, predictability, controllability of world development in the digital age. World development: problems of predictability and controllability. In: XIX International Likhachev Scientific Readings, 2019, pp. 137-140. DOI: https://doi.org/10.17759/langt.2018050201.

3. V. A. Lektorsky, Uncertainty, unpredictability and super-certainty. Contours of the future in the context of world cultural development: XVIII International Likhachev Scientific Readings 2018, pp, 114-116. DOI: http://doi.org/10.5281/zenodo.165453.

4. V.V. Mironov, Globalization and the threat of unification. Age of globalization. Research of modern global processes, 1(9) (2012) pp. 20-33. DOI: https://doi.org/10.31874/2309-1606-2019-241-154-173.

5. G.A. Prazdnikov, Culture in the space of life. SPbGATI, 2014. p. 480. DOI: https://doi.org/10.25146/1995-0861-2018-44-2-69. 
6. Ibid.

7. V.V. Mironov, Globalization and the threat of unification. Age of globalization. Research of modern global processes 1(9) 2012 pp. 20-33. DOI: https://doi.org/10.17223/15617793/434/9.

8. J. Baudrillard, Transparency of evil. Dobrosvet, 2006 p. 258. DOI: https://doi.org/10.21684/2411197X-2018-4-2-84-94.

9. D. V. Mordvintsev, D. V. Mordvintseva, The problem of training a designer: on the way to independent activity. Decorative art and subjectspatial environment. MGHPA Bulletin 2 (2016) pp. 203-208. DOI: https://doi.org/10.31866/26172674.2.1.2019.170873.

10. Yu. Ilyin, Generative art: when the artist removes his

hands. Computerra. DOI: https://doi.org/10.21146/ 2413-9084-2019-24-1-7-45.

11. Type.today. Magazine. What fonts will be relevant tomorrow? Timur Zima answers. DOI: https://doi.org/10.21146/2072-0726-2018-11-3-15165.

12. Yu.M. Lotman, Inside the thinking worlds. Iskusstvo-SPb, 1996 p. 464. DOI: https://doi.org/10.21146/2072-0726-2020-13-4-89101.

13. G.A. Prazdnikov, Culture in the space of life. SPbGATI, 2014 p. $480 . \quad$ DOI: https://doi.org/10.21146/2413-9084-2021-25-2-5-8.

14. D. V. Mordvintsev, Z. V. Mordvintseva, The problem of training a designer: on the way to independent activity. Decorative art and subjectspatial environment. MGHPA Bulletin 2 (2016) Part 2 pp. 203-208. DOI: https://doi.org/10.24411/23468408-2018-10002.

15. S.V. Kurasov, A.N. Lavrentyev, E.A. ZaevaBurdonskaya, A.V. Sazikov, Stroganovka: 190 years of Russian design. Russkiy Mir, 2015 p. 608. DOI: https://doi.org/10.1016/j.sbspro.2014.12.563.

16. T.B. Sidneva, Dialectics of frontiers in music. ABSdesign, 2014 p. 400 . DOI: https://doi.org/10.31874/2309-1606-2018-23-2192-218.

17. E.V. Dukov, Varevo entertainment. Entertainment and art. Aleteya, 2008 pp. 8-9.

18. F.W. Taylor, Principles of scientific management. Mag. "Controlling": Publishing house of standards, 1991 p. 104. 